\title{
Exhaustive exercise training enhances aerobic capacity in American alligator (Alligator mississippiensis)
}

\author{
John Eme $\cdot$ Tomasz Owerkowicz • \\ June Gwalthney · Jason M. Blank • \\ Bryan C. Rourke · James W. Hicks
}

Received: 2 April 2009/Revised: 20 May 2009/Accepted: 25 May 2009/Published online: 17 June 2009

(C) The Author(s) 2009. This article is published with open access at Springerlink.com

\begin{abstract}
The oxygen transport system in mammals is extensively remodelled in response to repeated bouts of activity, but many reptiles appear to be 'metabolically inflexible' in response to exercise training. A recent report showed that estuarine crocodiles (Crocodylus porosus) increase their maximum metabolic rate in response to exhaustive treadmill training, and in the present study, we confirm this response in another crocodilian, American alligator (Alligator mississippiensis). We further specify the nature of the crocodilian training response by analysing effects of training on aerobic [citrate synthase (CS)] and
\end{abstract}

Communicated by H. V. Carey.

J. Eme $(\square) \cdot$ T. Owerkowicz · J. Gwalthney ·

J. M. Blank · J. W. Hicks

Ecology and Evolutionary Biology, University of California,

Irvine, 321 Steinhaus Hall, Irvine, CA 92697-2525, USA

e-mail: jeme@uci.edu

URL: http://grad.bio.uci.edu/ecoevo/jeme

J. W. Hicks

URL: http://compphys.bio.uci.edu/hicks/

Comparative_Physiology/Welcome.html

T. Owerkowicz · J. M. Blank

Department of Orthopaedic Surgery, College of Health Sciences,

University of California, Irvine, CA 92697, USA

Present Address:

J. M. Blank

Biological Sciences, California Polytechnic State University,

San Luis Obispo, CA 93407-0401, USA

B. C. Rourke

Biological Sciences, California State University,

Long Beach, 1250 Bellflower Blvd, Peterson Hall 1 109,

Long Beach, CA 90840, USA anaerobic [lactate dehydrogenase (LDH)] enzyme activities in selected skeletal muscles, ventricular and skeletal muscle masses and haematocrit. Compared to sedentary control animals, alligators regularly trained for 15 months on a treadmill (run group) or in a flume (swim group) exhibited peak oxygen consumption rates higher by 27 and $16 \%$, respectively. Run and swim exercise training significantly increased ventricular mass $(\sim 11 \%)$ and haematocrit $(\sim 11 \%)$, but not the mass of skeletal muscles. However, exercise training did not alter CS or LDH activities of skeletal muscles. Similar to mammals, alligators respond to exercise training by increasing convective oxygen transport mechanisms, specifically heart size (potentially greater stroke volume) and haematocrit (increased oxygen carrying-capacity of the blood). Unlike mammals, but similar to squamate reptiles, alligators do not also increase citrate synthase activity of the skeletal muscles in response to exercise.

Keywords Alligator - Citrate synthase - Exercise . Metabolic rate $\cdot$ Oxygen consumption

$\begin{array}{ll}\text { Abbreviations } \\ \text { CF } & \text { Caudofemoralis } \\ \text { CS } & \text { Citrate synthase } \\ \text { DP } & \text { Diaphragmaticus } \\ \text { GC } & \text { Gastrocnemius } \\ \text { IAP } & \text { Intra-abdominal pressure } \\ \text { KWRS } & \text { Kruskal-Wallis rank sums } \\ \text { LDH } & \text { Lactate dehydrogenase } \\ Q_{\text {tot }} & \text { Cardiac output } \\ \text { RER } & \text { Respiratory exchange ratio } \\ \text { SC } & \text { Splenius capitis } \\ \text { SNK } & \text { Student Newman-Keuls post hoc test }\end{array}$


$\dot{V}_{\mathrm{A}} \quad$ Alveolar ventilation

$\dot{V}_{\mathrm{CO}_{2}} \quad$ Mass-specific carbon dioxide production rate

$\dot{V}_{\mathrm{O}_{2}} \quad$ Mass-specific oxygen consumption rate

WRS Wilcoxon rank sums

\section{Introduction}

The oxygen transport system in mammals is extensively remodeled in response to repeated bouts of activity. In mammals, chronic exercise training causes concomitant increases in both oxidative enzyme activities and convective oxygen transport and an overall increase in maximum oxygen consumption $\left(\dot{V}_{\mathrm{O}_{2}}\right.$ max) (e.g., human-Carter et al. 2000; horse-Evans and Rose 1988; rat-Gleeson et al. 1983; mouse-Kemi et al. 2002; dog-Musch et al. 1985). However, among non-mammalian vertebrates, the effects of chronic exercise training on oxygen transport are not well documented. Increases in catabolic enzyme activities have been measured for a chondrichthyan (Gruber and Dickson 1997), several osteichthyan fishes (e.g. Farrell et al. 1991; Davison 1997), two anuran amphibians (Cummings 1979; Miller and Camilliere 1981), an agamid lizard (Garland et al. 1987) and two birds (Butler and Turner 1988; Lundgren and Kiessling 1986). No consistent evidence exists for other nonmammalian vertebrates. At the whole-animal level, an increase in $\dot{V}_{\mathrm{O}_{2}}$ max in response to exercise training has been demonstrated in relatively few non-mammalian vertebrates, with data for two teleosts (chinook salmon-Gallaugher et al. 2001; dark barbel catfish-Liu et al. 2009), one archosaurian reptile (estuarine crocodile-Owerkowicz and Baudinette 2008) and one bird (tufted duck-Butler and Turner 1988). Studies in phylogenetically diverse lizards have failed to find a significant exercise training effect for skeletal muscle aerobic enzymatic activity or whole-animal aerobic metabolism (Conley et al. 1995; Garland et al. 1987; Gleeson 1979; Thompson 1997; A. M. Szucsik et al., unpublished). Consequently, lizards have been considered 'metabolically inflexible' (Gleeson 1979).

In contrast to lizards, a recent study suggests that crocodilians may have a more plastic metabolic response to exercise training (Owerkowicz and Baudinette 2008). Daily exhaustive exercise on a treadmill resulted in a significant increase in aerobic capacity $(+28 \%)$ and walking endurance $(+82 \%)$ in juvenile male estuarine crocodiles (Crocodylus porosus Schneider 1801). The purpose of our study was to determine whether exercise can increase $\dot{V}_{\mathrm{O}_{2}}$ in another crocodilian species, American alligator (Alligator mississippiensis Daudin 1801) and to ascertain if exercise training alters major aerobic or anaerobic enzyme activities of skeletal muscle. We subjected juvenile female alligators to either a swimming or running exhaustive exercise training protocol and compared them to a sedentary control group. After 15 months of training, we measured the rates of oxygen consumption and carbon dioxide production for alligators subjected to a modified graded exercise test on a treadmill. Following sacrifice and tissue harvest, we examined changes in animals' haematocrit and wet heart mass. We also measured the activity of citrate synthase and lactate dehydrogenase in selected skeletal muscles of exercise-trained and sedentary alligators.

\section{Materials and methods}

Animals

American alligator eggs $(N=35$; A. mississippiensis $)$ were obtained from the Rockefeller Wildlife Refuge (RWR) in Grand Chenier, LA, USA and transported by air freight to the University of California, Irvine (UCI). Eggs were potted in moist vermiculite and incubated at $30^{\circ} \mathrm{C}$. This ensured that all alligator hatchlings were female (confirmed by cloacal examination). After hatching (August-September 2005), alligators were group housed in $1 \times 2.5 \times 1 \mathrm{~m}$ fiberglass tanks at $30^{\circ} \mathrm{C}$ with free access to water and basking sites. Animals were fed an ad libitum diet of live goldfish or ground whole chicken, 2-3 times per week. Approval for animal use in this study was given by the UCI Institutional Animal Care and Use Committee (protocol \#1999-2123).

\section{Sham surgery}

From January-March 2006, alligators underwent a sham surgery as a control for other studies. At the time of surgery (5-7 month old animals), mean mass was $65 \pm 2.1 \mathrm{~g}$. Briefly, following anaesthesia induction with isoflurane (Isoflo ${ }^{\circledR}$; Abbott laboratories, North Chicago, IL, USA), the animal was intubated and artificially ventilated using a SAR-830 Ventilator (CWE, Ardmore, PA, USA), with a vaporiser (Foregger Fluomatic, Smithtown, NY, USA) providing $1-2 \%$ isoflurane. The pericardium and great vessels were exposed. The pericardium was incised to expose the ventricles and atria and sewn shut with 6-0 silk suture. The musculature, sternum and skin were sewn shut in succession with 3-0 silk suture (Ethicon, Somerville, NJ, USA). Following surgery, animals were artificially ventilated on room air until voluntary breathing resumed. Intramuscular injections of the antibiotic enrofloxacin (10 mg kg${ }^{-1}$; Baytril; Bayer Corporation, Shawnee Mission, KS, USA) and the analgesic flunixin meglumine ( $5 \mathrm{mg} \mathrm{kg}^{-1}$; Flunixamine; Fort Dodge, Madison, NJ, USA) were given at the conclusion of surgery, and enrofloxacin was given for two additional days post-operative. Food was withheld for 5-7 days following surgery. All animals were 
fully recovered (2.5-5 months post-operative) by the beginning of the 15-month exercise training protocol.

\section{Exercise training protocol}

At approximately 9 months of age (June 2006), alligators were randomly assigned to three groups: run, swim, and sedentary $(N=12,12$ and 11, respectively). Animals in the run and swim groups were exercised to exhaustion on approximately each Monday, Wednesday and Friday and every other Sunday on a treadmill $\left(1.0-2.0 \mathrm{~km} \mathrm{~h}^{-1}\right)$ or in a swim flume $\left(0.5-1.0 \mathrm{~km} \mathrm{~h}^{-1}\right)$ until sacrifice in OctoberDecember 2007. Our exercise training protocol was much longer than those typically employed in mammalian studies (e.g. Carter et al. 2000; Evans and Rose 1988; Gleeson et al. 1983; Kemi et al. 2002; Musch et al. 1985), and the long duration was chosen because previous studies on exercise training in squamates have not demonstrated skeletal muscle plasticity in response to training (Conley et al. 1995; Garland et al. 1987; Gleeson 1979; Thompson 1997; A. M. Szucsik et al., unpublished). Animals were encouraged to run or swim by tapping them on the tail by hand or with a pair of long forceps. Exercise bouts were kept at $\sim 5 \mathrm{~min}$ by gradually increasing flume and treadmill speeds over the training period, as animals grew. Five minutes is a typical endurance time for $1-2 \mathrm{~kg}$ crocodilians exercising at a $\sim 0.75-2.0 \mathrm{~km} \mathrm{~h}^{-1}$ (Farmer and Carrier 2000; Munns et al. 2005; Owerkowicz and Baudinette 2008). Endurance was defined as time to exhaustion (to the nearest $15 \mathrm{~s}$ ), at which point the animal failed to respond to repeated stimulation and was judged unable to maintain treadmill or flume speed. Animals in the sedentary group were not exercised and were only handled once every fortnight for the purpose of body size measurements. During transport to the treadmill room or the flume room for exercise, all animals were kept in darkened containers to minimise handling stress.

$\dot{V}_{\mathrm{O}_{2}}$ and $\dot{V}_{\mathrm{CO}_{2}}$ of exercise-trained and sedentary alligators

Following 15 months of exercise training (in September 2007), the run, swim and sedentary groups of alligators underwent a graded exercise test on a motorised treadmill in order to estimate $\dot{V}_{\mathrm{O}_{2}}$ peak. We refer to the highest oxygen consumption measured for alligators in this study at any single treadmill speed (last $30-40 \mathrm{~s}$ at each speed) or recovery (first 30-40 s following cessation of exercise) as ' $\dot{V}_{\mathrm{O}_{2}}$ peak', rather than ' $\dot{V}_{\mathrm{O}_{2}}$ max'. $\dot{V}_{\mathrm{O}_{2}}$ max is commonly used to indicate a steady state of sustained maximum oxygen consumption, measured during sustained locomotion at a steady speed. However, it is relatively difficult for crocodilians to reach a classic stable metabolic state on a treadmill, given their lack of cooperation to locomote on a treadmill and limited ability to sustain a rigorous exercise level (e.g. 3-7 min total, see Farmer and Carrier 2000; Munns et al. 2005; Owerkowicz and Baudinette 2008). In contrast to prior studies on crocodilians, we did not rest animals between successive speeds. Instead, we thoroughly exhausted alligators during a single bout of exercise by increasing treadmill speed every minute until exhaustion. Hence, given the short duration that animals spent at each treadmill speed, and that we define $\dot{V}_{\mathrm{O}_{2}}$ peak as the highest oxygen-consumption value measured during any one treadmill speed or recovery, we believe that $\dot{V}_{\mathrm{O}_{2}}$ peak is an appropriate distinction from $\dot{V}_{\mathrm{O}_{2}} \max$.

Alligators were fasted for 3-4 days prior to experimentation, and measures were made at $30^{\circ} \mathrm{C}$ in a temperaturecontrolled environmental chamber. Experiments were performed between 1400-000 hours for six consecutive days, and the training schedule of exercise-trained animals was suspended for 3-6 days prior to experimentation to ensure animals were fully recovered before the graded exercise test (Hartzler et al. 2006). At the time of the graded exercise test ( 24-month-old animals), mean mass was $1.1 \pm 0.2 \mathrm{~kg}$ for the run group, $1.2 \pm 0.1 \mathrm{~kg}$ for the swim group and $1.7 \pm 0.1 \mathrm{~kg}$ for the sedentary group. To collect expired gases, animals were fitted with a mask constructed from acetate sheeting. The mask had two holes (inlet and outlet) connected to flexible tubing (Tygon; $5 \mathrm{~mm} \mathrm{ID,} 2 \mathrm{~mm}$ wall). With the animal's mouth taped shut, the mask was affixed over its nostrils and sealed air-tight with Impregum (3 M ESPE, Seefeld, Germany). Room air was pulled through the mask by pumps at a rate of 1.0-4.4 $\mathrm{L} \mathrm{min}^{-1}$, depending on animal size, and expired air was sub-sampled $8 \mathrm{~cm}$ downstream of the nostrils (via $2 \mathrm{~mm}$ ID Tygon tubing) at a flow rate of $150 \mathrm{ml} \mathrm{min}^{-1}$. Bias flow through the mask was similar to rates published previously (Farmer and Carrier 2000; Hartzler et al. 2006; Munns et al. 2005; Owerkowicz and Baudinette 2008). Prior to the treadmill test, flow rates were tested across the range of animal sizes by rolling alligators to exhaustion and monitoring exhaled gases during subsequent recovery when the animals were breathing vigorously and frequently. Flow rates were then increased until carbon dioxide could not be detected escaping into the inlet tubing near the mask, which ensured collection of all exhaled gases and prevented rebreathing. Animals that were rolled were not a part of an exercise test for at least one week. Proper flow rates were applied to appropriately sized animals and ensured that no $\mathrm{CO}_{2}$ escaped into the inlet tubing. All flow rates were maintained using calibrated rotameters (Cole-Parmer, Vernon Hills, IL, USA); one rotameter maintained bias flow through the mask (downstream flow at $1.0-4.4 \mathrm{~L} \mathrm{~min}^{-1}$ ) and the other maintained an appropriate sub-sampling flow rate $\left(150 \mathrm{ml} \mathrm{min}^{-1}\right)$ for the gas analysers. Wet, sub-sampled air was pulled first through a carbon dioxide analyser (CD-3A, Applied 
Electrochemistry Instruments, Pittsburgh, PA, USA), then through a Drierite (anhydrous calcium sulphate; W.A. Hammond Drierite Co., Xenia, OH, USA) column, and finally through an oxygen analyser (S-3A, Applied Electrochemistry Instruments, Pittsburgh, PA, USA). Signals from the carbon dioxide and oxygen analysers were collected on a computer at $20 \mathrm{~Hz}$ using an A/D MP100 board and AcqKnowledge data-acquisition software (v.3.8.1 Biopac, Goleta, CA, USA).

An alligator was placed on the treadmill and remained stationary for 1-2 min ('pre-exercise'). The animal was then stimulated to run as steadily as possible for $1 \mathrm{~min}$ at each of the following successively increasing speeds: 0.5 , 1.0, 1.5 and $2.0 \mathrm{~km} \mathrm{~h}^{-1}$. Expired gases were collected continuously, and $\dot{V}_{\mathrm{O}_{2}}$ and $\dot{V}_{\mathrm{CO}_{2}}$ were estimated from the respective mean values in expired air during the last 30 $40 \mathrm{~s}$ of pre-exercise and each treadmill speed. Animals were run until exhaustion, with exhaustion defined as refusal to run or attempt to run for $\sim 10 \mathrm{~s}$. Exhaustion occurred at either 1.5 or $2.0 \mathrm{~km} \mathrm{~h}^{-1}$. Expired gases were collected after exercise ended ('recovery') and the mean values in expired air from the first 30-40 s were used to estimate recovery $\dot{V}_{\mathrm{O}_{2}}$ and $\dot{V}_{\mathrm{CO}_{2}}$. Prior experiments have shown that some reptiles have a locomotor constraint on oxygen transport during exercise (Carrier 1987; Farmer and Hicks 2000; Frappell et al. 2002; Munns et al. 2004; Owerkowicz et al. 1999), but previous studies on alligators have not demonstrated a locomotor constraint on cardiopulmonary convection during exercise (Farmer and Carrier 2000; Munns et al. 2005). Since we did not rest alligators between successive increasing treadmill speeds (Farmer and Carrier 2000; Munns et al. 2005), it was necessary, therefore, to determine if gas exchange during immediate recovery from exercise was different from gas exchange during the highest treadmill speed. Equations derived from Withers (1977) were used to calculate $\dot{V}_{\mathrm{O}_{2}}$ and $\dot{V}_{\mathrm{CO}_{2}}$ rates at STPD for pre-exercise, each treadmill speed and recovery:

$\dot{V}_{\mathrm{O}_{2}}=\frac{\dot{V}_{\mathrm{E}}\left(F_{\mathrm{I}_{\mathrm{O}_{2}}}-F_{\mathrm{E}_{\mathrm{O}_{2}}}\right)-F_{\mathrm{I}_{\mathrm{O}_{2}}}\left(\dot{V}_{\mathrm{CO}_{2}}\right)}{1-F_{\mathrm{I}_{\mathrm{O}_{2}}}}$

$\dot{V}_{\mathrm{CO}_{2}}=\frac{\dot{V}_{\text {out }}\left(F_{\mathrm{E}_{\mathrm{CO}_{2}}}-F_{\mathrm{I}_{\mathrm{CO}_{2}}}\right)-F_{\mathrm{I}_{\mathrm{CO}_{2}}}\left(\dot{V}_{\mathrm{O}_{2}}-\dot{V}_{\mathrm{EWL}_{\mathrm{L}}}\right)}{1-F_{\mathrm{I}_{\mathrm{CO}_{2}}}}$

where $\dot{V}_{\mathrm{O}_{2}}$ is oxygen consumption rate $\left(\mathrm{ml} \mathrm{O}_{2} \mathrm{~min}^{-1}\right)$, $\dot{V}_{\mathrm{CO}_{2}}$ is carbon dioxide production rate $\left(\mathrm{ml} \mathrm{CO}_{2} \min ^{-1}\right)$, $\dot{V}_{\text {out }}$ is excurrent airflow rate across the mask $\left(\mathrm{ml} \mathrm{min}^{-1}\right.$; $\mathrm{STP}), \dot{V}_{\mathrm{E}}$ is dried excurrent airflow rate ( $\mathrm{ml} \cdot \mathrm{min}^{-1}$; STPD), $F_{\mathrm{I}}$ is fraction of inspired gas, $F_{\mathrm{E}}$ is fraction of expired gas and $\dot{V}_{\text {EWL }}$ is evaporative water loss rate $\left(\mathrm{ml} \mathrm{H}_{2} \mathrm{O} \cdot \mathrm{min}^{-1}\right)$. $\dot{V}_{\text {EWL }}$ was not measured directly, but calculated using published minute ventilation rates for alligators during exercise and recovery (Farmer and Carrier 2000), with the assumption of full relative humidity of exhaled air. At the time of the $\dot{V}_{\mathrm{O}_{2}}$ peak test, sedentary animals were significantly heavier than animals in either exercise group (ANOVA: $F_{2,32}=3.3, P=0.025$ ). It is likely that the energy expended during exercise training limited the growth of exercise-trained alligators, compared to sedentary controls; however, exercise-trained alligators did not appear chronically stressed. We express $\dot{V}_{\mathrm{O}_{2}}$ in mass-specific terms because regression of raw values against mass yielded a high correlation coefficient $\left(R^{2}=0.88\right.$, Simple Linear Regression, $P<0.0001$ ).

$\dot{V}_{\mathrm{O}_{2}}$ peak and $\dot{V}_{\mathrm{CO}_{2}}$ peak values were taken as the highest oxygen consumption and carbon dioxide production rates, respectively, measured during any one treadmill speed or during recovery. Following the graded exercise test, each animal in the run and swim groups resumed its regular exercise regimen until it was sacrificed (13 months later).

Euthanasia, blood sample collection and tissue harvest

All alligators were sacrificed at age 26-27 months (October-December 2007). Mean mass at the time of sacrifice was $1.3 \pm 0.2 \mathrm{~kg}$ for the run group, $1.4 \pm 0.1 \mathrm{~kg}$ for the swim group and $2.0 \pm 0.1 \mathrm{~kg}$ for the sedentary group. In order to assure that animals had fully recovered from their most recent bout of exercise, exercise training was suspended 2-4 days before each animal's sacrifice (Hartzler et al. 2006). Animals were fasted for 2-6 days prior to sacrifice. Following induction of anaesthesia with isoflurane, the animal was intubated and artificially ventilated (2-5\% isoflurane; see 'Sham surgery', above). Blood samples were taken from the supraspinal vein using preheparinised $3 \mathrm{ml}$ syringes, and haematocrit determined in triplicate $( \pm 1 \%)$ using a haematocrit microcentrifuge (3 min at 9,500g, Model Z231M; Hermle Labortechnik, Wehingen, Germany) and Micro-Hematocrit Capillary Tube Reader (Lancer ${ }^{\circledR}$; Brunswick Company, St. Louis, MO, USA). Skeletal muscles were harvested sequentially (gastrocnemius, caudofemoralis, diaphragmaticus and splenius capitis) while the animal continued to be artificially ventilated under anaesthesia. The gastrocnemius (knee and ankle flexor), caudofemoralis (femoral retractor and rotator) and diaphragmaticus (liver retractor) were all likely stimulated during exercise, whereas splenius capitis (neck extensor) was likely not involved in running and swimming exercise motions and was chosen as a 'control' skeletal muscle. While under anesthesia and following removal of the skeletal muscles, animals were euthanised by excision of the heart. The atria and great vessels were carefully dissected away from both ventricles. The ventricles and skeletal muscles were blotted lightly with gauze, and respective wet masses measured on an analytical 
balance $( \pm 0.001 \mathrm{~g}$; Mettler AE 163; Mettler-Toledo Inc., Columbus, OH, USA). Samples of each skeletal muscle tissue (taken from the middle portion of each muscle) were promptly freeze-clamped with copper tongs pre-cooled in liquid nitrogen and stored at $-80^{\circ} \mathrm{C}$ until homogenisation for enzyme assays.

\section{Enzyme assays}

We determined citrate synthase activity (CS; units $\mathrm{g}^{-1}$ tissue) and lactate dehydrogenase activity ( $\mathrm{LDH}$; units $\mathrm{g}^{-1}$ tissue) in triplicate at $30^{\circ} \mathrm{C}$ for each skeletal muscle using methods modified from Seebacher et al. (2003). Only fresh homogenates, kept on ice, were used for assays. Frozen tissues $(0.045-0.070 \mathrm{~g})$ were homogenised on ice using nine volumes of extraction buffer ( $\mathrm{pH}$ 7.5). Extraction buffer consisted of $50 \mathrm{mmol} \mathrm{L}^{-1}$ imidazole/ $\mathrm{HCl}, 2 \mathrm{mmol} \mathrm{L}{ }^{-1}$ $\mathrm{MgCl}_{2}, 5 \mathrm{mmol} \mathrm{L}{ }^{-1}$ ethylene diamine tetra-acetic acid (EDTA), $1 \mathrm{mmol} \mathrm{L}^{-1}$ reduced glutathione and $0.1 \%$ Triton X-100. Using a microplate reader (PowerWave XS; Biotech Instruments, Winooski, Vermont, USA), CS activity was estimated as reduction of 5,5' dithiobis-(2-nitrobenzoic) acid (DTNB) at $412 \mathrm{~nm}$ and LDH activity as absorbance of $\mathrm{NADH}$ at $340 \mathrm{~nm}$. Aliquots of original homogenates were further diluted by a factor of 2 for LDH samples and by 300 for CS samples. The CS assay medium consisted of $100 \mathrm{mmol} \mathrm{L}^{-1}$ Tris/HCl (pH 8.0), $1.0 \mathrm{mmol} \mathrm{L}^{-1}$ DTNB, $3.0 \mathrm{mmol} \mathrm{L}^{-1}$ acetyl $\mathrm{CoA}$ and $5.0 \mathrm{mmol} \mathrm{L}^{-1}$ oxaloacetate. The millimolar extinction coefficient of DTNB is 14.1. The LDH assay medium consisted of $100 \mathrm{mmol} \mathrm{L}^{-1}$ potassium phosphate buffer $\left(\mathrm{KH}_{2} \mathrm{PO}_{4} / \mathrm{K}_{2} \mathrm{HPO}_{4}, \mathrm{pH} 7.0\right), 0.16 \mathrm{mmol}$ $\mathrm{L}^{-1} \mathrm{NADH}$ and $4.0 \mathrm{mmol} \mathrm{L}^{-1}$ pyruvate. The millimolar extinction coefficient of NADH is 6.22. Sedentary animals were significantly heavier than exercise-trained animals at the time of sacrifice and tissue harvest (ANOVA: $F_{2,32}=3.3, P<0.001$ ), but expressing enzyme activities in mass-specific terms does not change results of the statistical analyses. Therefore, we chose to present enzyme activities in units $\mathrm{g}^{-1}$ tissue for comparison with a previous report of American alligator enzyme plasticity (Seebacher et al. 2003).

\section{Statistical analyses}

Mass-specific $\dot{V}_{\mathrm{O}_{2}}$ and $\quad \dot{V}_{\mathrm{CO}_{2}}\left(\mathrm{ml} \mathrm{gas} \mathrm{kg}^{-1} \mathrm{~min}^{-1}\right)$ was compared using a Kruskal-Wallis rank sums (KWRS; $\alpha=0.05$ ) test between exercise groups (run, swim, sedentary) within each treadmill speed (mean value calculated from individual average expired gas values taken from last $30-40 \mathrm{~s}$ at $0.5,1.0,1.5$ and $2.0 \mathrm{~km} \mathrm{~h}^{-1}$ ) and for recovery (mean value calculated from individual average expired gas values taken from last 30-40 s) and $\dot{V}_{\mathrm{O}_{2}}$ peak. Respiratory exchange ratio (RER; $\dot{V}_{\mathrm{CO}_{2}} / \dot{V}_{\mathrm{O}_{2}}$ ) was compared between exercise groups within each treadmill speed and recovery using a KWRS test $(\alpha=0.05)$. A significant $\chi^{2}$ from a KWRS test was followed by post hoc comparisons using Wilcoxon rank sums (WRS) tests with Bonferroni adjustment $(\alpha=0.0167)$. Non-parametric tests were used because of platykurtic data. For ventricular and skeletal muscle wet mass, a one-way analysis of variance (ANOVA) compared mass-specific values (gram of tissue $\mathrm{kg} \mathrm{animal}^{-1}$ ) between exercise groups, and enzyme activities were also compared between groups using a one-way ANOVA. Haematocrit was compared between exercise groups using a one-way ANOVA on arcsine square root transformed fractions. A significant ANOVA $(\alpha=0.05)$ was followed by a Student Newman-Keuls (SNK) post hoc test $(\alpha=0.05)$.

Mass-specific $\dot{V}_{\mathrm{O}_{2}}$ and $\dot{V}_{\mathrm{CO}_{2}}$ and RER were also compared within each exercise group between sequential treadmill speeds using repeated-measures ANOVA, followed by post hoc comparisons using one-tailed paired $t$ tests with Bonferroni adjustment $(\alpha=0.025)$. Between the highest treadmill speed and recovery, a two-tailed paired $t$ test with Bonferroni adjustment was used $(\alpha=0.025)$.

Throughout the text, mean values are given \pm SE.

\section{Results}

\section{Exercise training}

The mean number of separate exhaustive exercise bouts was $178 \pm 14$ and $196 \pm 1$ for the run and swim groups, respectively, from the age of $\sim 9$ to $\sim 25$ months (prior to graded exercise test). For an individual exercise bout, animals in the run group exercised for an average of $4.5 \pm 0.06 \mathrm{~min}$ and in the swim group for $5.5 \pm 0.06 \mathrm{~min}$ (grand mean of weekly mean values taken to the nearest $15 \mathrm{~s})$. These averages yield an approximate total of $70 \mathrm{~min}$ per month of exercise ( $5 \mathrm{~min} \times 14$ days per month), a value similar to the one likely obtained by Farmer and Carrier (2000) and Munns et al. (2005), but less than the more rigorous training schedule employed by Owerkowicz and Baudinette (2008).

$\dot{V}_{\mathrm{O}_{2}}, \dot{V}_{\mathrm{CO}_{2}}$ and RER

Compared to animals in the sedentary group, American alligators regularly exercised for 15 months showed a significant elevation in maximal oxygen consumption $\left(\dot{V}_{\mathrm{O}_{2}}\right.$ peak; KWRS test: $\chi_{2,32}^{2}=12.34, P<0.01$, WRS test with $\alpha=0.0167$ for run $>$ sedentary: $\chi^{2}=9.82, P<0.01$ and for swim $>$ sedentary: $\chi^{2}=7.67, P<0.01$; Figs. 1,2$) . \dot{V}_{\mathrm{O}_{2}}$ peak occurred at the recovery stage for 11 of 12 animals in the run group, for 9 of 12 animals in the swim group, and for 6 of 11 animals in the sedentary group. Recovery $\dot{V}_{\mathrm{O}_{2}}$ was 

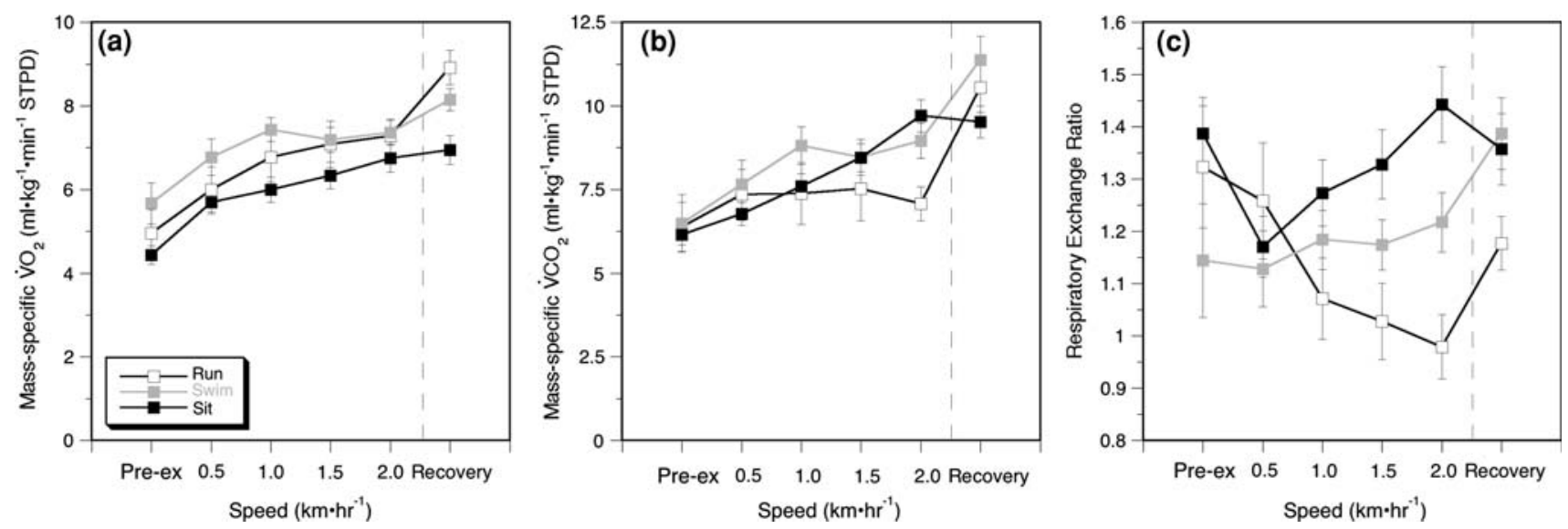

Fig. 1 Mean oxygen consumption rate (a), carbon dioxide production rate (b) and respiratory exchange ratio (c) before (Pre-ex), during $\left(0.5-2.0 \mathrm{~km} \mathrm{~h}^{-1}\right)$ and after (recovery) a graded treadmill exercise test for alligators from different exercise groups, run, swim and sedentary

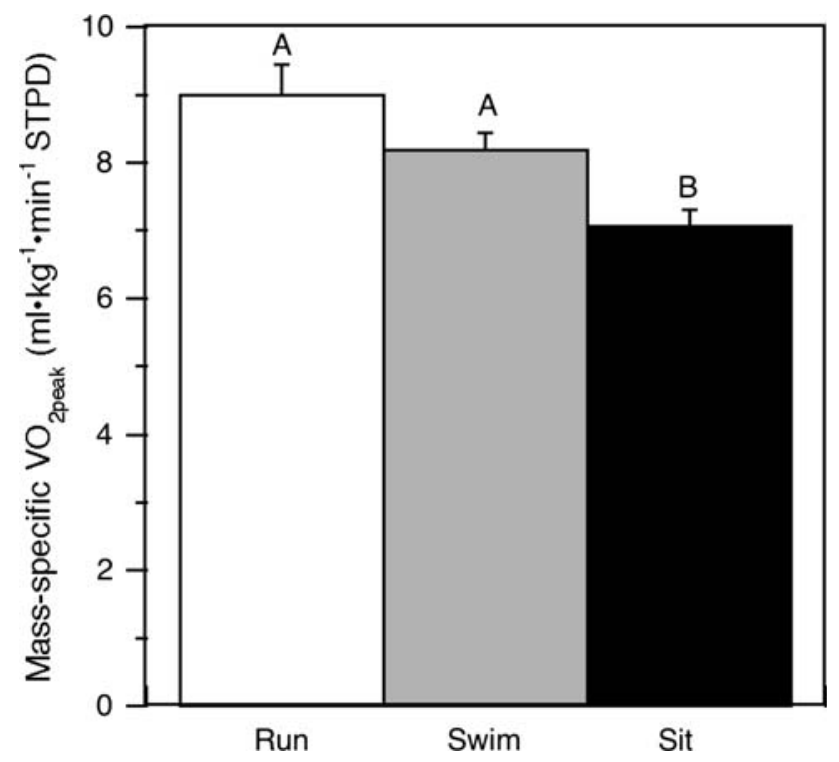

Fig. 2 Mean mass-specific peak oxygen consumption rate recorded during a graded treadmill exercise test for alligators from different exercise groups, run, swim and sedentary (sit). Run and swim groups had significantly higher $\dot{V}_{\mathrm{O}_{2}}$ peak than the sedentary (sit) group. Uppercase letters above error bars indicate significant differences between groups derived from Kruskal-Wallis rank sums test $(\alpha=0.05)$ followed by Wilcoxon rank sums test with Bonferroni correction $(\alpha=0.0167)$. Error bars are SE

significantly higher for the run group, compared to sedentary (KWRS test: $\chi_{2,32}^{2}=13.71, P<0.01$, WRS test: $\chi^{2}>9.4$, $P<0.01) . \dot{V}_{\mathrm{O}_{2}}$ at $1.0 \mathrm{~km} \mathrm{~h}^{-1}$ was significantly higher for the swim group, compared to sedentary (KWRS test: $\chi_{2,32}^{2}=$ 7.03, $P=0.03$, WRS test: $\left.\chi^{2}=7.33, P<0.01\right)$. Compared to the sedentary group, $\dot{V}_{\mathrm{CO}_{2}}$ trended lower at $2.0 \mathrm{~km} \mathrm{~h}^{-1}$ for the run group (KWRS test: $\chi_{2,32}^{2}=6.94, P=0.03$, WRS test: $\chi^{2}=5.44, P=0.02$ ) but not for the swim group. Compared to sedentary animals, RER was significantly (sit). All groups showed a significant increase in $\dot{V}_{\mathrm{O}_{2}}$ with speed. The run group showed no trend towards increasing $\dot{V}_{\mathrm{CO}_{2}}$ with increasing treadmill speed, and hence, displayed lower RERs than the swim and sedentary (sit) groups. Error bars are SE

lower for the run group at 1.5 (KWRS test: $\chi_{2,32}^{2}=8.38$, $P=0.02$, WRS test: $\left.\chi^{2}=7.33, P<0.01\right)$ and $2.0 \mathrm{~km} \mathrm{~h}^{-1}$ (KWRS test: $\chi_{2,32}^{2}=10.38, P<0.01$, WRS test: $\chi^{2}=6.76$, $P<0.01$ ) and nearly significant during recovery (KWRS test: $\chi_{2,32}^{2}=7.18, \quad P=0.03$, WRS test: $\chi^{2}=3.88$, $P=0.05)$. Compared to the swim group, RER was lower for the run group at $2.0 \mathrm{~km} \mathrm{~h}^{-1}$ (KWRS test: $\chi_{2,32}^{2}=10.38$, $P<0.01$, WRS test: $\left.\chi^{2}=5.61, P=0.018\right)$ and recovery (KWRS test: $\chi_{2,32}^{2}=7.18, P=0.03$, WRS test: $\chi^{2}=5.88$, $P=0.015)$.

All three groups also showed a significant increase in $\dot{V}_{\mathrm{O}_{2}}$ and $\dot{V}_{\mathrm{CO}_{2}}$ with increasing treadmill speed (repeated-measures ANOVA: $\left.F_{4,18}>9.59, P<0.001\right)$. For all three groups, $\dot{V}_{\mathrm{O}_{2}}$ at $0.5 \mathrm{~km} \mathrm{~h}^{-1}$ was significantly greater when compared to pre-exercise values (one-tailed paired $t$ test with Bonferroni correction, $\alpha=0.025, P<0.01$ ), indicating the alligators were not overly agitated at the beginning of the exercise test. However, given considerable inter-individual variability in $\dot{V}_{\mathrm{O}_{2}}$ at each speed, no significant difference was detected in $\dot{V}_{\mathrm{O}_{2}}$ between successive speeds (one-tailed paired $t$ test with Bonferroni correction, $\alpha=0.025, P>0.05$ ), except within the run group between speed 0.5 and $1.0 \mathrm{~km} \mathrm{~h}^{-1}(P<0.01)$. At the end of the exercise, both the run and swim group showed a significant rise in $\dot{V}_{\mathrm{O}_{2}}$ and $\dot{V}_{\mathrm{CO}_{2}}$ during recovery (two-tailed paired $t$ test with Bonferroni correction, $\alpha=0.025, P<0.02)$. The sedentary group showed a significant rise in $\dot{V}_{\mathrm{O}_{2}}$ during recovery (two-tailed paired $t$ test with Bonferroni correction, $\alpha=0.025$, $P=0.015)$, but not in $\dot{V}_{\mathrm{CO}_{2}}(P=0.56)$.

The RER steadily decreased with increasing treadmill speed, then spiked sharply during recovery for animals in the run group. In contrast, RER remained relatively constant during increasing treadmill speed for the swim group, then spiked during recovery. For the sedentary group, RER 
increased with increasing treadmill speed, then dropped during recovery. The only significant differences were within the run and swim group, where RER spiked significantly during recovery (two-tailed paired $t$ test with Bonferroni correction, $\alpha=0.025, P<0.02$; Fig. 1).

Ventricular and skeletal muscle mass and haematocrit

Mass-specific ventricular wet mass (combined ventricles; gram of tissue $\mathrm{kg} \mathrm{animal}^{-1}$ ) was significantly increased by an average of $11.5 \%$ in run and swim animals, compared to sedentary animals (one-way ANOVA: $F_{2,32}=9.31, P<$ 0.001 , SNK $\alpha=0.05$; Fig. 3a). For haematocrit, a similar average increase relative to sedentary animals was seen for both run $(12.7 \%)$ and swim (9.9\%) alligators (ANOVA on arcsine square root transformed fractions: $F_{2,32}=4.62$, $P=0.017$, SNK $\alpha=0.05$; Fig. 3b). The skeletal muscles tested (gastrocnemius, caudofemoralis, diaphragmaticus and splenius capitis) did not show any significant change in massspecific wet mass with exercise training (Table 1; one-way ANOVA: $F_{2,32}<3.32, P>0.05$ ); however, data for the caudofemoralis was suggestive of increasing muscle mass for both run and swim animals (one-way ANOVA: $\left.F_{2,32}=3.34, P=0.053\right)$.

\section{Enzyme assays}

No consistent trend for an increase or decrease in either aerobic (CS) or anaerobic (LDH) enzyme activities was seen across skeletal muscles tested (one-way ANOVA: $F_{2,11 \text { or } 13}<1.98, P>0.18$; Fig. 4$)$.

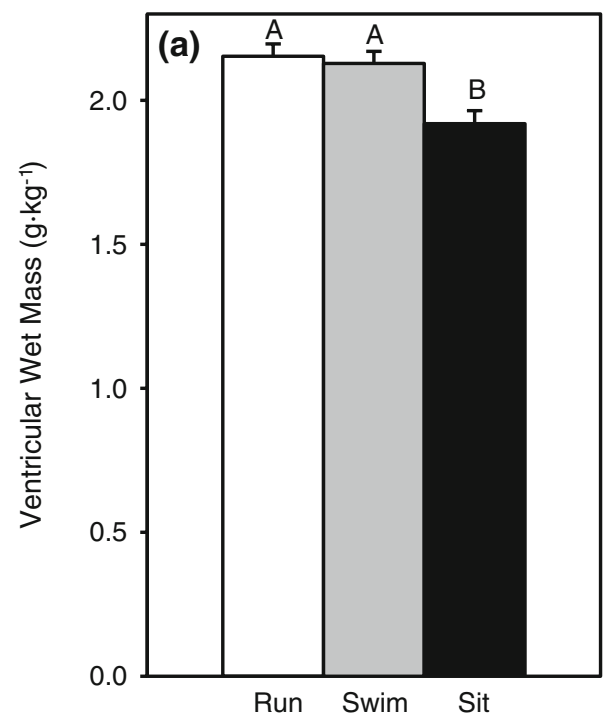

Fig. 3 Mean mass-specific ventricular wet mass (a) and mean haematocrit (b) for alligators from different exercise groups, run, swim and sedentary (sit). Uppercase letters above error bars indicate significant differences between groups within each metric derived

\section{Discussion}

Exhaustive exercise training increases maximum $\dot{V}_{\mathrm{O}_{2}}$ in crocodilians

Exhaustive exercise training increased peak oxygen consumption $\left(\dot{V}_{\mathrm{O}_{2}}\right.$ peak) of a non-avian archosaur, American alligator. This result is in agreement with a recent report that exercise training increased $\dot{V}_{\mathrm{O}_{2}}$ max in another crocodilian, estuarine crocodile (Owerkowicz and Baudinette 2008). Compared to sedentary control animals, alligators habitually trained on the treadmill (run) or in the flume (swim) exhibited $\dot{V}_{\mathrm{O}_{2}}$ peak values 27 and $16 \%$ higher, respectively. The magnitude of this training effect is similar to the result obtained by Owerkowicz and Baudinette (2008) on juvenile estuarine crocodiles trained on a treadmill (post-training $\dot{V}_{\mathrm{O}_{2}}$ max higher, on average, by $28 \%$ than pre-training values). The exercise sessions in each study followed similar protocols, with animals exercised to exhaustion during each training bout, although the frequency and duration of training differed. This approach was quite different from exercise training protocols employed in other vertebrate studies, which have found that training intensities corresponding to $75 \% \dot{V}_{\mathrm{O}_{2}} \max$ can elicit significant increases in peak or maximum $\dot{V}_{\mathrm{O}_{2}}$ (Adams et al. 1975; Bedford et al. 1979; Kieffer et al. 1998). Except when habituated to an exercise protocol (Farmer and Carrier 2000), crocodilians had previously shown an 'all-or-nothing' $\dot{V}_{\mathrm{O}_{2}}$ response to exercise (Munns et al. 2005; Owerkowicz and Baudinette 2008), i.e., any treadmill speed elicits an anaerobic response which

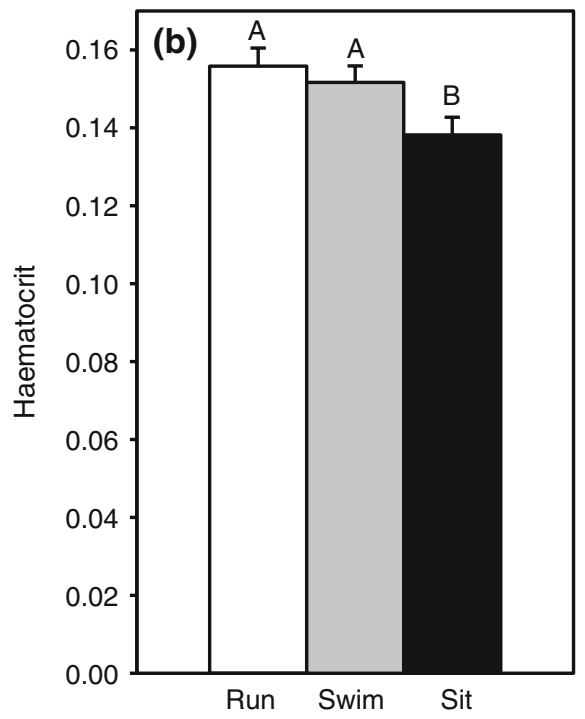

from ANOVA followed by SNK post hoc test $(\alpha=0.05)$ (for haematocrit, fractional values were arcsine square root transformed). Error bars are SE 
Table 1 Mass-specific skeletal muscle masses for selected skeletal muscles for alligators from different exercise groups: run, swim and sedentary

\begin{tabular}{lllll}
\hline Group $(N)$ & $\begin{array}{l}\text { Gastrocnemius } \\
(\mathrm{g} \mathrm{kg} \mathrm{animal}\end{array}$ & $\begin{array}{l}\text { Caudofemoralis } \\
\left(\mathrm{g} \mathrm{kg} \mathrm{animal}^{-1}\right) \pm \mathrm{SE}\end{array}$ & $\begin{array}{l}\text { Diaphragmaticus } \\
\left(\mathrm{g} \mathrm{kg} \mathrm{animal}^{-1}\right) \pm \mathrm{SE}\end{array}$ & $\begin{array}{l}\text { Splenius capitis } \\
(\mathrm{g} \mathrm{kg} \mathrm{animal}\end{array}$ \\
\hline Run (12) & $1.85 \pm 0.04$ & $16.03 \pm 0.29$ & $4.60 \pm 0.09$ & $2.83 \pm 0.05$ \\
Swim (12) & $1.83 \pm 0.04$ & $15.72 \pm 0.26$ & $4.18 \pm 0.22$ & $2.85 \pm 0.09$ \\
Sedentary (11) & $1.86 \pm 0.05$ & $14.94 \pm 0.37$ & $4.80 \pm 0.13$ & $2.91 \pm 0.05$ \\
\hline
\end{tabular}

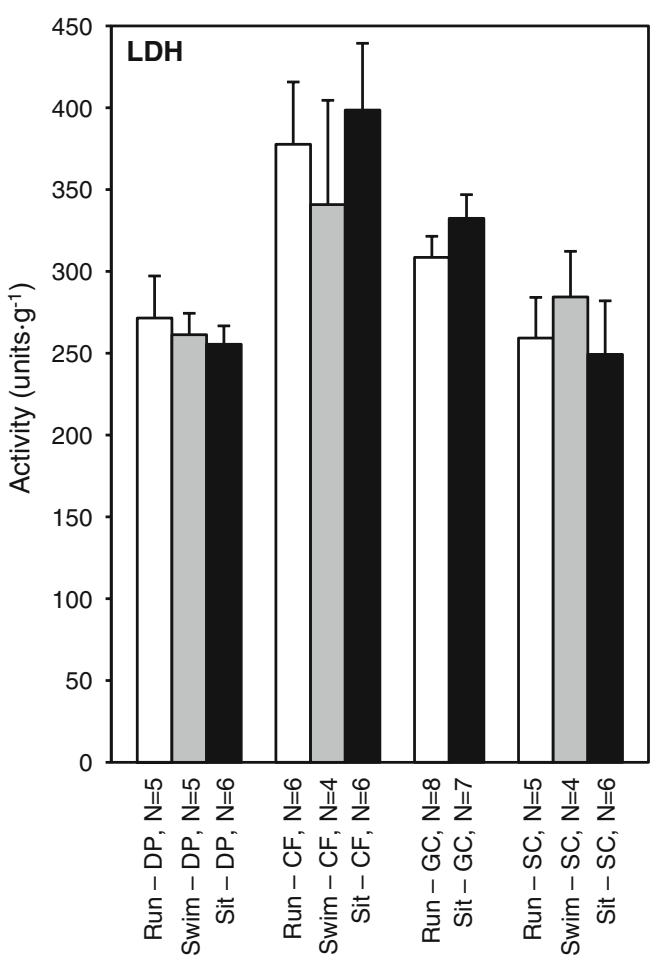

Fig. 4 Mean lactate dehydrogenase (LDH) and citrate synthase (CS) activities for skeletal muscles at $30^{\circ} \mathrm{C}$ for subsets of alligators from different exercise groups, run, swim and sedentary (sit). DP

suggests that energy demand exceeds $\dot{V}_{\mathrm{O}_{2}}$ max. Therefore, flume and treadmill speeds were chosen to allow individual $\sim 5$ min training bouts over the course of the study.

In Owerkowicz and Baudinette (2008), juvenile male crocodiles were kept on a strict diet to limit their growth and maintain an approximately constant body mass ( $\sim 1 \mathrm{~kg}$ ) and were exercised more intensively (up to four times a day, 6 days each week for 16 weeks). In the present study, diet and growth of the juvenile female alligators were not limited, and the exercise frequency was lower (once a day, 7 times every 2 weeks) but continued over a much longer period (15 months). These data suggest that exhaustive exercise elicits a training effect in crocodilians of both sexes at variable periods of ontogenetic growth using different levels of training frequency.

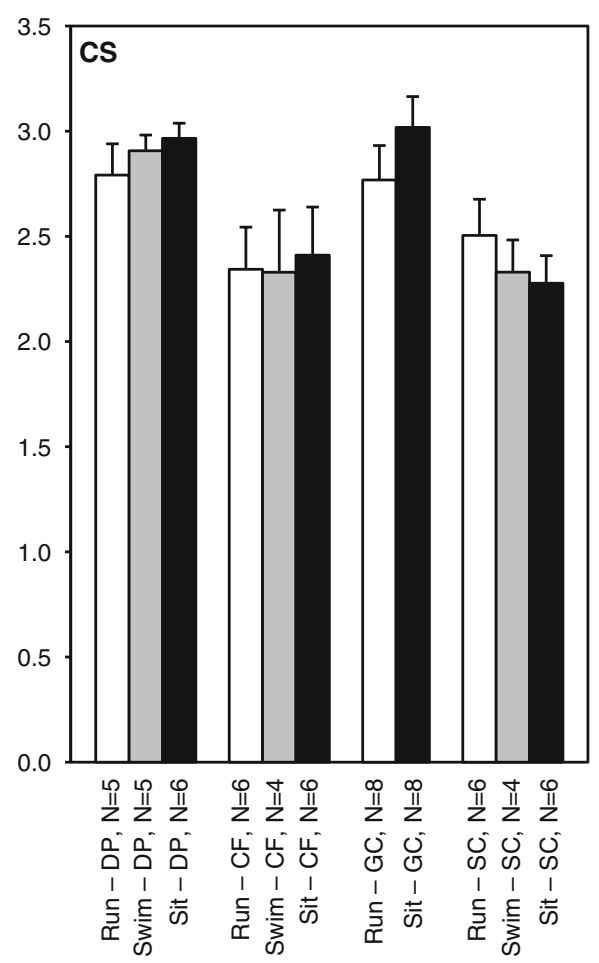

diaphragmaticus, $C F$ caudofemoralis, $G C$ gastrocnemius, $S C$ splenius capitis. Aerobic (CS) and anaerobic (LDH) enzyme activity appeared unaffected by exercise training. Error bars are SE

Comparison with gas exchange data for other crocodilians

$\dot{V}_{\mathrm{O}_{2}}$ peak of treadmill-trained alligators averaged $9.0 \mathrm{ml}$ $\mathrm{O}_{2} \cdot \mathrm{kg}^{-1} \mathrm{~min}^{-1}$, that of flume-trained alligators- $8.2 \mathrm{ml}$ $\mathrm{O}_{2} \mathrm{~kg}^{-1} \min ^{-1}$, and that of sedentary alligators$7.1 \mathrm{ml} \mathrm{O}_{2} \mathrm{~kg}^{-1} \min ^{-1}$ (Fig. 2). These values are very similar to the $\dot{V}_{\mathrm{O}_{2}}$ max obtained in previous studies on American alligator $\left(8.0-9.3 \mathrm{ml} \mathrm{O}_{2} \mathrm{~kg}^{-1} \mathrm{~min}^{-1}\right)$ and estuarine crocodile $\left(8.5 \mathrm{ml} \mathrm{O}_{2} \mathrm{~kg}^{-1} \mathrm{~min}^{-1}\right)$ habituated to treadmill exercise (Farmer and Carrier 2000; Munns et al. 2005; Owerkowicz and Baudinette 2008). Results of our study are in agreement with Farmer and Carrier (2000), showing that alligators can demonstrate a graded $\dot{V}_{\mathrm{O}_{2}}$ response with exercise intensity (i.e., significant increase in $\dot{V}_{\mathrm{O}_{2}}$ with increasing speed), in contrast to previous reports 
indicating an 'all or nothing' response for crocodilians to graded exercise (Munns et al. 2005; Owerkowicz and Baudinette 2008).

It is likely that the high RERs during 'pre-exercise' were a result of handling stress (metabolic acidosis) and hypoventilation (respiratory acidosis) that occurs when one picks up, holds and masks a crocodilian (i.e., they tend to struggle and hypoventilate). Following 'pre-exercise', animals were running on a treadmill, and $\mathrm{CO}_{2}$ was quickly blown off during frequent breathing. With increasing treadmill speed, animals in the run and swim groups generally had lower RERs relative to sedentary animals. This observation reflects that chronic exercise training in alligators (regardless of the nature of the training regime-run or swim) can induce a more aerobic physiology capable of carrying (increased haematocrit) and delivering (increased heart size) more oxygen as exertion approaches maximal levels.

Plasticity of oxygen transport in crocodilians, squamates and mammals

Similar to mammals, American alligator demonstrated increased $\dot{V}_{\mathrm{O}_{2}}$ (Carter et al. 2000; Evans and Rose 1988; Gleeson et al. 1983; Kemi et al. 2002; Musch et al. 1985), haematocrit (Brun et al. 2000; Ajmani et al. 2003) and heart size with exercise training (Richey and Brown 1998; Rowell 1974; Scheuer and Tipton 1977; Shephard and Balady 1999). Previous studies have failed to elicit an exercise training response in $\dot{V}_{\mathrm{O}_{2}}$ for phylogenetically diverse squamates (Conley et al. 1995; Garland et al. 1987; Gleeson 1979; Thompson 1997; A. M. Szucsik et al., unpublished) and do not report consistent changes in cardiac morphology or haematocrit. For example, Garland et al. (1987) reported statistically higher haematocrit for exercise-trained Ctenophorus (Amphibolurus) nuchalis; however, haematocrit also tended to increase for sedentary, captive $C$. (A.) nuchalis compared to field-fresh lizards. Increased haematocrit can be a sign of over-training in human athletes (Brun et al. 2000; Gaudard et al. 2003) and may indicate that our exercise regime was stressful. However, crocodilian haematocrit is between a third and half that of humans, and the relatively moderate but significant increase in haematocrit demonstrated by exercisetrained alligators may represent an important and chronic mechanism to increase oxygen transport. Exercise training studies on lizards have not demonstrated an increase in ventricular size due to exercise training, with either no change in heart mass in response to exhaustive exercise training (Gleeson 1979) or a decrease in heart mass in response to exercise training (Garland et al. 1987). Importantly, increased heart mass can mediate an adaptive increase in stroke volume and $\dot{V}_{\mathrm{O}_{2}} \max$ in mammals
(Gleeson 1979; Richey and Brown 1998; Rowell 1974; Scheuer and Tipton 1977), thereby aiding this convective step of the oxygen cascade.

In alligators, it has been demonstrated that venous return from the peripheral tissues to the heart is not limited by their locomotion (Munns et al. 2005), although in certain lizards the circulation limits the oxygen cascade during locomotion (Farmer and Hicks 2000; Frappell et al. 2002; Munns et al. 2004). Elevated intraabdominal pressure (IAP) limits venous return in Varanus exanthematicus, with peak venous return occurring after strenuous exercise has ceased (Munns et al. 2004). V. mertensi showed a decreased blood convection requirement $\left(Q_{\mathrm{tot}} / \dot{V}_{\mathrm{O}_{2}}\right)$ with a large arterial-venous oxygen content difference and rightshifted Bohr curve indicating that circulation $\left(Q_{\text {tot }}\right)$ limited the oxygen cascade (Frappell et al. 2002). Similarly, Iguana iguana showed a large increase in venous return following the end of strenuous treadmill exercise (Farmer and Hicks 2000). In contrast, venous return increased along with IAP in alligators during exercise and decreased during recovery, suggesting that alligators, unlike most squamates, are able to consistently return blood to their heart during strenuous exercise (Munns et al. 2005). It is possible that an increase in venous return during exercise stimulated the observed ventricular enlargement, as is thought to occur in mammals (McMullen et al. 2005; Pluim et al. 2000).

However, previous studies, which found no apparent constraints on convective oxygen transport during exercise in alligators (lung ventilation-Farmer and Carrier 2000; venous return-Munns et al. 2005), stand in contrast to our finding in this study: an increase in $\dot{V}_{\mathrm{O}_{2}}$ following cessation of exercise (recovery) indicates possible locomotor constraint(s) on oxygen transport during exercise or $\dot{V}_{\mathrm{A}} / \dot{Q}$ inhomogeneity. The multicameral lungs of alligators allow for relatively good $\dot{V}_{\mathrm{A}} / \dot{Q}$ matching under resting conditions in anesthetised and conscious animals (Powell and Gray 1989; Powell and Hopkins 2004), but it is not known how $\dot{V}_{\mathrm{A}} / \dot{Q}$ values change with exercise in crocodilians. It appears that exercise reduces the efficiency of $\mathrm{O}_{2}$ exchange in many mammals and $V$. exanthematicus, but not in emu (Dromaius novaehollandiae; reviewed in Powell and Hopkins 2004). Our continuous, exhaustive exercise treadmill test may have limited optimal lung filling due to axial movements not observed when alligators run at a constant treadmill speed for multiple minutes (i.e. a 'steady state'; Farmer and Carrier 2000; Munns et al. 2005; Owerkowicz and Baudinette 2008), and the observed increased $\dot{V}_{\mathrm{O}_{2}}$ during recovery from a continuous exhaustive exercise bout could have resulted from the recruitment of unventilated or unperfused regions of the lung.

Handling stress of alligators during the 15 months of exercise training could be a confounding factor in our study. Handling of exercise-trained animals before a bout 
of exercise consisted of picking-up the animal, placing her into a dark container and transporting her to the treadmill or flume room (the treadmill room was often the vivarium room where the animals were housed). It is known that chronic stress can cause cardiomyopathy (e.g., Sharkey et al. 2005; Wittstein et al. 2005), however, no reported case, in either animal studies or human studies, correlates hypertrophic cardiomyopathy with increased aerobic performance. In humans, hypertrophic cardiomyopathy is a genetic disorder associated with a reduction in peak oxygen consumption, and lower peak oxygen consumption has been used to differentiate mild hypertrophic cardiomyopathy from an 'athlete's heart' (for a review see, Lauschke and Maisch 2009). It is, therefore, not likely that handling stress caused exercise-trained alligators to have increased heart mass and increased aerobic capacity. In addition, exercise-trained animals did not show signs of chronic stress (e.g., wasting, refusal to eat, aggression).

Seebacher et al. (2003) demonstrated that American alligators show thermal compensation for both CS and LDH activities. For example, when measured at $15^{\circ} \mathrm{C}$, tail muscle extracts collected during the winter demonstrate higher enzyme activities than summer muscle extracts. Our enzymatic activity levels for $\mathrm{LDH}\left(\sim 350\right.$ units $\left.\mathrm{g}^{-1}\right)$ in caudofemoralis were very similar to values obtained for crocodilians acclimated to $\sim 30^{\circ} \mathrm{C}$ by Seebacher et al. (2003) and Seebacher and James (2008), whereas our values for $\mathrm{CS}\left(\sim 2.3\right.$ units $\left.\mathrm{g}^{-1}\right)$ in caudofemoralis are only slightly lower. It appears that temperature, but not exercise training, is a potent modulator of enzyme capacity in crocodilians.

Unlike the marked increase in aerobic enzyme capacity observed following long or short-term aerobic training in mammals (Baldwin et al. 1973; Holloszy and Booth 1976; Talanian et al. 2007), our data on American alligator are in agreement with previous molecular and biochemical research demonstrating a lack of plasticity in skeletal muscle at a molecular level for squamates when measured at a common temperature (Conley et al. 1995; Garland et al. 1987; Gleeson 1979; Szucsik et al. 2008; A. M. Szucsik et al., unpublished; Thompson 1997). CS activities in the ventricle and pyruvate kinase activity in the liver were elevated in $C$. (A.) nuchalis following an 8-week training schedule (Garland et al. 1987), however, Garland et al. (1987) also found that sedentary lizards had higher aerobic enzyme activity in thigh extensor muscles than exercise-trained lizards, contrary to what would be expected following an exercise training regime. Recently, it was demonstrated that chronic electrical stimulation for 8 weeks increases mitochondrial biogenesis in a hindlimb muscle of $V$. exanthematicus (Schaeffer et al. 2007), but in a separate study, 32 treadmill training bouts at $75 \%$ of $\dot{V}_{\mathrm{O}_{2}}$ max over 8 weeks did not increase $\dot{V}_{\mathrm{O}_{2}}$ max or alter myosin heavy chain expression in skeletal muscles of $V$. exanthematicus (A. M. Szucsik et al., unpublished). It remains to be tested whether a long-term and exhaustive training protocol, used in the present study and that on the estuarine crocodile (Owerkowicz and Baudinette 2008), can elicit an increase in heart mass, haematocrit or $\dot{V}_{\mathrm{O}_{2}} \max$ in a squamate.

Acknowledgments The authors sincerely thank the following individuals for invaluable help in these studies: Ruth Elsey (RWR) for access to alligators and alligator eggs and continuing support of our research, Brad Moon for arranging egg transport, George Lauder for donation of flow straighteners for our semi-laminar flume, Beth Brainerd for the loan of the propeller flowmeter (for calibrating the flume) and Rudi Limburg for prompt treadmill and flume repair work. Special thanks go to Amanda Szucsik for incubating the eggs, critical reading of early drafts of this manuscript and sharing her recent findings on exercise training in savannah monitor lizards. Most importantly, we would like to thank the following students for their assistance with exercise training of the alligators: Krista Felbinger, Saemyi Moon, Jennifer Bautista, Lindsay Peltz, Dore Pei and Tim Cho; this study would not have been possible without their hard work. JMB and TO were supported for part of this study by National Institutes Health Training Grant 2T32AR047752 to the Multidisciplinary Exercise Science Programme at UC Irvine. National Science Foundation Grant IOB 0445680 to JWH provided funding for this research.

Open Access This article is distributed under the terms of the Creative Commons Attribution Noncommercial License which permits any noncommercial use, distribution, and reproduction in any medium, provided the original author(s) and source are credited.

\section{References}

Adams WC, Bernauer EM, Dill DB, Bomar Jr JB (1975) Effects of equivalent sea-level and altitude training on $\dot{V}_{\mathrm{O}_{2}}$ max and running performance. J Appl Physiol 39:262-266

Ajmani RS, Fleg JL, Demehin AA, Wright JG, O'Connor F, Heim JM, Tarien E, Rifkind JM (2003) Oxidative stress and hemorheological changes induced by acute treadmill exercise. Clin Hemorheol Microcirc 28:9-40

Baldwin KM, Winder WW, Terjung RL, Holloszy JO (1973) Glycolytic enzymes in different types of skeletal muscle: adaptation to exercise. Am J Physiol 225:962-966

Bedford TG, Tipton CM, Wilson NC, Oppliger RA, Gisolfi CV (1979) Maximum oxygen consumption of rats and its changes with various experimental procedures. J Appl Physiol 47:12781283

Brun JF, Bouchahda C, Chaze D, Benhaddad AA, Micallef JP, Mercier J (2000) The paradox of hematocrit in exercise physiology: which is the "normal" range from a hemorheologist's viewpoint? Clin Hemorheol Microcirc 22:287-303

Butler PJ, Turner DL (1988) Effect of training on maximal oxygen uptake and aerobic capacity of locomotory muscles in tufted ducks, Aythya fuligula. J Physiol 401:347-359

Carrier DR (1987) Lung ventilation during walking and running in four species of lizards. Exp Biol 47:33-42

Carter H, Jones AM, Barstow TJ, Burnley M, Williams C, Doust JH (2000) Effect of endurance training on oxygen uptake kinetics during treadmill running. J Appl Physiol 89:1744-1752 
Conley KE, Christian KA, Hoppeler H, Weibel ER (1995) Heart mitochondrial properties and aerobic capacity are similarly related in a mammal and a reptile. J Exp Biol 198:739-746

Cummings JW (1979) Physiological and biochemical adaptations to training in Rana pipiens. J Comp Physiol 134:345-350

Davison W (1997) The effects of exercise training on teleost fish, a review of recent literature. Comp Biochem Physiol A 117:67-75

Evans DL, Rose RJ (1988) Cardiovascular and respiratory responses to submaximal exercise training in the thoroughbred horse. Pflügers Arch 411:316-321

Farmer CG, Carrier DR (2000) Ventilation and gas exchange during treadmill locomotion in the American alligator (Alligator mississippiensis). J Exp Biol 203:1671-1678

Farmer CG, Hicks JW (2000) Circulatory impairment induced by exercise in the lizard Iguana iguana. J Exp Biol 203:2691-2697

Farrell AP, Johansen JA, Suarez RK (1991) Effects of exercisetraining on cardiac performance and muscle enzymes in rainbow trout, Oncorhynchus mykiss. Fish Physiol Biochem 9:303-312

Frappell P, Schultz T, Christian K (2002) Oxygen transfer during aerobic exercise in a varanid lizard Varanus mertensi is limited by the circulation. J Exp Biol 205:2725-2736

Gallaugher PE, Thorarensen H, Kiessling A, Farrell AP (2001) Effects of high intensity exercise training on cardiovascular function, oxygen uptake, internal transport and osmotic balance in Chinook salmon (Oncorhynchus tschawytscha) during critical speed swimming. J Exp Biol 204:2861-2872

Garland T Jr, Else PL, Hulbert AJ, Tap P (1987) Effects of endurance training and captivity on activity metabolism of lizards. Am J Physiol 252:R450-R456

Gaudard A, Varlet-Marie E, Bressolle F, Mercier J, Brun JF (2003) Hemorheological correlates of fitness and unfitness in athletes: moving beyond the apparent "paradox of hematocrit"? Clin Hemorheol Microcirc 28:161-173

Gleeson TT (1979) The effects of training and captivity on the metabolic capacity of the lizard Sceloporus occidentalis. J Comp Physiol 129:123-128

Gleeson TT, Mullin WJ, Baldwin KM (1983) Cardiovascular responses to treadmill exercise in rats: effects of training. J Appl Physiol 54:789-793

Gruber SJ, Dickson KA (1997) Effects of endurance training in the Leopard shark, Triakis semifasciata. Physiol Biochem Zool 70:481-492

Hartzler LK, Munns SL, Bennett AF, Hicks JW (2006) Recovery from an activity-induced metabolic acidosis in the American alligator, Alligator mississippiensis. Comp Biochem Physiol A 143:368-374

Holloszy JO, Booth FW (1976) Biochemical adaptations to endurance exercise in muscle. Annu Rev Physiol 38:273-291

Kemi OJ, Loennechen JP, Wisløff U, Ellingsen O (2002) Intensitycontrolled treadmill running in mice: cardiac and skeletal muscle hypertrophy. J Appl Physiol 93:1301-1309

Kieffer JD, Alsop D, Wood CM (1998) A respirometric analysis of fuel use during aerobic swimming at different temperatures in Rainbow trout (Oncorhynchus mykiss). J Exp Biol 201:3123-3133

Lauschke J, Maisch B (2009) Althlete's heart or hypertrophic cardiomyopathy. Clin Res Cardiol 98:80-88

Liu Y, Cao ZD, Fu SJ, Peng JL,Wang YX (2009) The effect of exhaustive chasing training and detraining on swimming performance in juvenile darkbarbel catfish (Peltebagrus vachelli). J Comp Physiol B. doi:10.1007/s00360-009-0365-1

Lundgren BO, Kiessling KH (1986) Catabolic enzyme activities in the pectoralis muscle of premigratory and migratory juvenile Reed Warblers Acrocephalus scirpaceus (Herm). Oecologia 68:529-532

McMullen JR, Sadoshima J, Izumo S (2005) Physiological versus pathological cardiac hypertrophy. In: Walsh RA (ed) Molecular mechanisms of cardiac hypertrophy and failure. Taylor \& Francis, London, pp 117-136

Miller K, Camilliere JJ (1981) Physical training improves swimming performance of the African clawed frog Xenopus laevis. Herpetologica 37:1-10

Munns SL, Hartzler LK, Bennett AF, Hicks JW (2004) Elevated intraabdominal pressure limits venous return during exercise in Varanus exanthematicus. J Exp Biol 207:4111-4120

Munns SL, Hartzler LK, Bennett AF, Hicks JW (2005) Terrestrial locomotion does not constrain venous return in the American alligator, Alligator mississippiensis. J Exp Biol 208:3331-3339

Musch TI, Haidet GC, Ordway GA, Longhurst JC, Mitchell JH (1985) Dynamic exercise training in foxhounds. I. Oxygen consumption and hemodynamic responses. J Appl Physiol 59:183-189

Owerkowicz T, Baudinette RV (2008) Exercise training enhances aerobic capacity in juvenile estuarine crocodiles (Crocodylus porosus). Comp Biochem Physiol A 150:211-216

Owerkowicz T, Farmer CG, Hicks JW, Brainerd EL (1999) Contribution of gular pumping to lung ventilation in Monitor lizards. Science 284:1661-1663

Pluim BM, Zwinderman AH, van der Laarse A, van der Wall EE (2000) The athlete's heart: a meta-analysis of cardiac structure and function. Circ 101:336-344

Powell FL, Gray AT (1989) Ventilation-perfusion relationships in alligators. Resp Physiol 78:83-94

Powell FL, Hopkins SR (2004) Comparative physiology of lung complexity: implications for gas exchange. News Physiol Sci 19:55-60

Richey PA, Brown SP (1998) Pathological versus physiological left ventricular hypertrophy: a review. J Sports Sci 16:129-141

Rowell LB (1974) Human cardiovascular adjustments to exercise and thermal stress. Physiol Rev 54:75-159

Schaeffer PJ, Nichols SD, Lindstedt SL (2007) Chronic electrical stimulation drives mitochondrial biogenesis in skeletal muscle of a lizard, Varanus exanthematicus. J Exp Biol 210:3356-3360

Scheuer J, Tipton CM (1977) Cardiovascular adaptations to physical training. Annu Rev Physiol 39:221-251

Seebacher F, James RS (2008) Plasticity of muscle function in a thermoregulating ectotherm (Crocodylus porosus): biomechanics and metabolism. J Appl Physiol 294:R1024-R1032

Seebacher F, Guderley H, Elsey RM, Trosclair PLIII (2003) Seasonal acclimatisation of muscle metabolic enzymes in a reptile (Alligator mississippiensis). J Exp Biol 206:1193-1200

Sharkey SW, Lesser JR, Zenovich AG, Maron MS, Lindberg J, Longe TF, Maron BJ (2005) Acute and reversible cardiomyopathy provoked by stress in women from the United States. Circ 111:472-479

Shephard RJ, Balady GJ (1999) Exercise as cardiovascular therapy. Circ 99:963-972

Szucsik AM, Rourke BC, Hicks JW (2008) Aplasticity of skeletal muscle in Varanus exanthematicus following compensatory overload. In: 2008 American physiological society intersociety meeting. The integrative biology of exercise-V, Hilton Head, South Carolina, USA, Abstract 20.7

Talanian JL, Galloway SDR, Heigenhauser GJF, Bonen A, Spriet LL (2007) Two weeks of high-intensity aerobic interval training increases the capacity for fat oxidation during exercise in women. J Appl Physiol 102:1439-1447

Thompson GG (1997) Do training and captivity affect maximal metabolic rate of Varanus gouldii (Squamata: Varanidae)? Amphib Reptil 18:112-116

Withers PC (1977) Measurement of $\dot{V}_{\mathrm{O}_{2}}, \dot{V}_{\mathrm{CO}_{2}}$, and evaporative water loss with a flow-through mask. J Appl Physiol 42:120-123

Wittstein IS, Thiemann DR, Lima JAC, Baughman KL, Schulman SP, Gerstenblith G, Wu KC, Rade JJ, Bivalacqua TJ, Champion HC (2005) Neurohumoral features of myocardial stunning due to sudden emotional stress. N Engl J Med 352:539-548 